\title{
Cancer patients' expectations regarding empowering knowledge and nurse advocacy in Finland and Spain
}

\author{
Heli Vaartio-Rajalin ${ }^{1}$, Helena Leino-Kilpi ${ }^{1}$, Adelaida Zabalegui ${ }^{2}$, Monserrat Valverde ${ }^{2}$, Anna \\ Mantecon², Pauli Puukka ${ }^{3}$ \\ 1. Department of Nursing Science, University of Turku, Finland. 2. Hospital Clinic de Barcelona, Spain. 3. National Institute \\ for Health and Welfare, Turku, Finland.
}

Correspondence: Heli Vaartio-Rajalin. Address: Department of Nursing Science, University of Turku, 20014, Finland. Email: heli.vaartio-rajalin@novia.fi

Received: November 15, 2013

Accepted: March 26, 2014

Online Published: April 26, 2014

DOI : $10.5430 /$ cns.v2n3p8

URL: http://dx.doi.org/10.5430/cns.v2n3p8

\section{Abstract}

Introduction: Cancer patients are not a homogenous group with the same information needs, but rather a vast range of individuals with different backgrounds, needs, life situations, and stressors. The patients' knowledge and selfdetermination expectations vary during illness trajectory, and they may need counseling by a nurse as patient advocate. Therefore, counseling of cancer patients should be seen as a process aimed at providing the patients with empowering information.

Aim: This study aims to explicate adult cancer patients' expectations regarding empowering knowledge and counseling nurse advocacy in relation to the significant demographical, situational and clinical factors that affect these expectations during the illness trajectory. Furthermore the aim is to describe the possible differences between two culturally different settings, i.e. northern and southern Europe.

Methods: A survey was conducted using the Expected Knowledge of Hospital Patients ${ }^{\circledR}$ instrument, accompanied by self-determination, advocacy and empowerment related questions, among informants recruited from two university hospitals in Finland $(n=332)$ and one university hospital in Spain $(n=483)$.

Results: Several demographical, situational and clinical factors such as age, educational background, actual clinical symptoms and perceived emotional distress of the patient correlated statistically significantly with the knowledge and advocacy expectations. In both datasets, the bio-physiological knowledge represented the most highly expected knowledge domain, and knowledge about social issues or economic matters the least expected domains. Spanish informants had higher knowledge expectations in all sum variables and a higher need for counseling advocacy than Finnish informants. Despite that, the Spanish informants showed slightly higher perceived empowerment in self-determination and advocacy than the Finnish informants.

Conclusions: Patient education in oncologic context should be based on a continuous analysis of patients' emotional distress and clinical symptoms instead of routine praxis. Therefore, a patient-centered approach to education should be structured and applied to make sure that patients are fully informed about their condition and treatment options and to ensure that patients feel respected in the clinical encounter.

\section{Key words}

Patient education, Counseling, Knowledge expectations, Empowerment, Advocacy 


\section{I ntroduction}

Cancer is one of the most common diseases in Finland. About 11,600 adult men and 10,700 adult women receive a cancer diagnosis every year ${ }^{[1]}$. The most common cancer forms in Finland are prostate, lung, colon and ventricular cancer for men and breast, colon, uterus and ventricular cancer for women ${ }^{[2]}$. Cancer, as an illness, is nowadays a very common topic for discussion in media, and many famous actors and politicians, for example, tell honestly about their cancer and its care. Furthermore, the official health care system, Cancer Foundation and Cancer Patient Foundation all have a lot of information made available for new cancer patients and their near ones. Spain is one of the six most populous countries in Europe ${ }^{[3]}$. In 2013, the predicted incidence of new cancer cases is 208,500-209,500 (105,000-105,500 men and 103,500-104,000 women). In 2012, the four most common cancer types were prostate, colorectal, lung and stomach cancer in men, and breast, colorectal, lung and stomach cancer in women ${ }^{[4]}$. In Spain, cancer is one of the most prevalent diseases and, in recent years, patients and families have started to openly talk about it. Individuals in public and influential positions in society have also presented their stories in the media, and even created Cancer Research Foundations. There are also cancer patient associations providing assistance to the affected patients and families.

However, cancer still in many cases means a life crisis or, at least, has an impact on several aspects of one's life for a long time and can therefore be seen as a chronic disease. As it comes to patient education, this re-conceptualization has not yet translated into current health care practices and systems ${ }^{[5]}$. Cancer patients have varying informational needs during their illness trajectory, and their involvement in decision-making concerning their care is a central part of an effective and equal care process. However, there is evidence of both discontinuity and disempowerment of patient education in oncologic context ${ }^{[6]}$, resulting in a significant risk of care fragmentation and suboptimal patient outcomes ${ }^{[5]}$. For example, information provided by healthcare professionals at different stages of illness is often experienced by patients as irrelevant, unreliable and difficult to understand. Healthcare providers possibly underestimate patients' needs for information ${ }^{[7]}$, or they may have their own perceptions of what kind of information should be introduced to them ${ }^{[8]}$, or by whom. Therefore, despite all good intentions, patient empowerment in the form of participation in one's own care may be hindered by restricting the patient’s access to knowledge and insight and/or by inhibiting the patient's self-care ${ }^{[9]}$.

In order to tackle these difficulties, an individual and contextual patient counseling praxis should be tailored for every oncologic patient, starting from what is known about the patient's individual knowledge expectations and reactions to information from different sources during illness trajectory. Cancer patients are not a homogenous group with the same knowledge expectations, but rather a vast range of individuals with different demographical and cultural backgrounds, needs, life situations, and stressors. Therefore, counseling of cancer patients is to be taken as a process aimed at providing the patients with empowering information.

\section{Background}

\section{Nurses as counseling patient advocates}

In this study, the term counseling refers to the recognition of individual health and cancer care related information and its exchange between patients and healthcare providers, not to any form of therapy. Counseling starts with an analysis of a patient's cognitive resources and expectations, i.e., the needs related to the acquisition and processing of information through perception, action, and problem solving ${ }^{[10]}$. Furthermore, the different demographical, situational and clinical factors affecting the patient's cognition, knowledge expectations and decision-making preferences should be identified. For example, gender, age, educational background, employment status, time elapsed since diagnosis, physical condition, mood, and acute admission to hospital are associated with cancer patients' knowledge expectations ${ }^{[1,12]}$, but there is still a question how these factors are connected with knowledge expectations. This analysis is vital in order to provide truly individual, contextual and empowering patient counseling. Otherwise, the next steps of the process, namely, responding to these expectations by informing patients, further explicating the information if needed, assisting patients in processing the information, coordinating informative interventions with other healthcare team members or analyzing the patients' 
comprehension and knowledge later on, can neither fulfill the ethical or legal demands of patient participation nor satisfy the patients' knowledge expectations.

These diagnostic procedures are seen as a task of cancer nurses ${ }^{[13]}$. However, there are scarce research reports on how to assess the knowledge expectations of the patients ${ }^{[14]}$ and only a few instruments have been developed for that purpose. These instruments do not sufficiently consider the current phase of illness trajectory, or the different individual factors related to knowledge expectations. The Supportive Care Needs Survey ${ }^{\left[{ }^{[C N S}-S F 34,15\right]}$ includes five domains of which one concerns adult cancer patients' information needs. The EORTC Quality of Life questionnaire ${ }^{[16]}$ aims to evaluate the information received by cancer patients and its effect on their quality of life. The focus is on biophysical issues, as is also in the Patient Information Need Questionnaire ${ }^{[\mathrm{PINQ}, 17]}$. In the Toronto Informational Needs Questionnaire (TINQ), the subscales include even psychosocial items ${ }^{[18]}$, but no financial or ethical issues. The Information Satisfaction Questionnaire ${ }^{[I S Q, 19]}$ focuses, as its name implies, on information satisfaction, and another ${ }^{[20]}$ focuses on information preferences among female cancer patients. All these instruments include items related to patients' information needs, but a need assessment does not infer that a patient desires anything in particular ${ }^{[15]}$, and therefore, in this study, the focus is on knowledge expectations. Furthermore, all the above listed instruments are applied at the beginning of the illness trajectory, and the Patient Learning Needs Scale ${ }^{[21]}$ is the only one to be used upon discharge. This is despite the fact that over half of cancer patients change their decision-making preferences, at least, once during the illness trajectory ${ }^{[23]}$. There is an obvious lack of a diagnostic tool correcting these inconsistencies and to be used by cancer nurses in their everyday practice.

The changes in patients' knowledge expectations or decision-making preferences are neither being systematically identified or analyzed, nor responded to. By continuously analyzing patients' needs and by promoting or defending their rights to information and decision-making, nurses will fulfill the ethical demands of their role as patient advocates. In nursing ethics the term advocacy is usually defined as a role of a nurse who promotes and safeguards the well-being and interests of the patients by ensuring that they are aware of their rights and have access to the information they need to give their informed consent ${ }^{[23]}$. This type of advocacy is proactive by nature. However, there is also another perspective to advocacy, which is obtained from the patients themselves, stating that patient advocacy does not only mean the promotion and protection of patients' legal rights but also their ethical rights and skilled clinical care per se ${ }^{[24]}$. Both these definitions of advocacy can be seen also in light of triadic advocacy ${ }^{[25]}$ or reactive advocacy, meaning advocacy as protection against a third-party factor, such as misconduct in the care process, threat by a relative, or minimal health care resources. This perspective on advocacy emphasizes the actual or possible problems concerning patients' autonomy and right to participate in decision-making as triggers of advocacy.

\section{Empowerment}

Patient advocacy is especially important when the patient is disempowered due to cognitive challenges caused by age, illness or treatments, or language problems ${ }^{[26,27]}$. Cancer patients are usually near or past middle-age, and cancer itself as an illness, its' medical management and especially the side-effects ${ }^{[28]}$, as well as the different transitions during the illness trajectory are known to affect cancer patients' cognitive skills and informational expectations ${ }^{[11,29]}$. Most cancer patients do not meet the criteria for cognitive impairment, but they might still experience subtle deterioration in cognitive functioning that can impact their daily living and quality of life ${ }^{[30]}$.

It has also been reported that cancer patients from different ethnic backgrounds have different knowledge expectations: white patients tended to be more willing to talk about cancer and seek help, whereas certain ethnic minorities tended to be hesitant to talk about cancer or seek help, possibly due to the stigmatized nature of cancer in some cultures ${ }^{[31]}$. White patients also tend to place the highest priority on their own individual experiences and interests, and they want to have control of their own bodies and lives, whereas in some cultures, for example, Hispanic or Asian, patients tend to emphasize the welfare of the family ${ }^{[32]}$. However, research concerning informational expectations of cancer patients has mainly been conducted in Western white population, and with a focus on written information. These reports give an incomplete picture 
of oncologic patients' knowledge expectations ${ }^{[33]}$, and if we let this picture guide us in patient counseling, it can, at worst, be disempowering instead of empowering. Empowerment can be defined, on individual and community level, as an enabling process of active and equal participation in decision-making, awareness and commitment to change, and the capacity to transform one's own realities, or being able to make choices ${ }^{[34]}$. These attributes of empowerment are antecedents of patient advocacy, such as the patient's activity in communication and collaboration within the patient-nurse relationship ${ }^{[24]}$.

Empowering patient education has been identified ${ }^{[35]}$ to integrate six types of knowledge required by patients to manage their health problems: bio-physiological (e.g., knowledge about illness, symptoms, treatment and complications), functional (e.g., mobility, rest, nutrition and body hygiene), experiential (e.g., emotions and hospital experiences), social (e.g., families, other patients and patient unions), ethical (e.g., rights, duties, participation in decision-making and confidentiality) and financial (e.g., costs and financial benefits). These knowledge domains have been validated in several studies in different contexts.

\section{Aim}

This research study aims to explore adult cancer patients' knowledge expectations, their expectations related to nurse advocacy and the identification of the significant demographical, situational and clinical factors connected with these knowledge and nurse advocacy expectations during the illness trajectory among patients. The data were collected in two countries, Spain and Finland in order to describe the possible differences between two culturally different settings, i.e. northern and southern Europe. The study results will contribute to further research and development of a model of an empowering counseling praxis for cancer patients throughout illness trajectory, with a focus on diagnosing knowledge expectations.

This study is a part of the on-going Empowering Patient Education project initiated at the Department of Nursing Science, University of Turku ${ }^{[36]}$. The project aims to analyze and evaluate patient education in different fields of health care and nursing by improving the quality of health education, by developing instruments for the evaluation of the quality and outcomes of patient education, and by fostering discussion about the importance of patient education.

\section{Methods and ethical considerations}

This cross-sectional study was conducted as a self-administered questionnaire survey with the purpose of gathering information about the incidence and distribution of, and the relationships that exist between certain variables in a pre-determined population ${ }^{[37]}$.

The survey was conducted using the Expected Knowledge of Hospital Patients ${ }^{\circledR}$ instrument ${ }^{[38]}$. This instrument measures the earlier mentioned six types of empowering knowledge needs of patients with a chronic disease: bio-physiological, functional, social, experiential, ethical and financial ${ }^{[35]}$. Moreover, the survey contains questions about perceived actual clinical symptoms and emotional distress, and items related to nurse advocacy expectations, concerning knowledge about right to self-determination, knowledge about advocacy, perceived empowerment in self-determination and self-advocacy, self-determination expectations, counseling advocacy expectations, as well as proactive and reactive advocacy expectations. Developed in Finland, the EKHP ${ }^{\circledR}$ instrument has been validated in several studies in different contexts and countries, including Spain ${ }^{[39]}$.

The survey data were collected from two university hospitals (with a total of four oncologic wards, four policlinics) in Finland ( $\mathrm{n}=332$, a stratified convenience sample) and one university hospital (with an outpatient unit, policlinic, clinical trial unit and two hematology-oncology wards) in Spain ( $n=483$, stratified convenience sample). Inclusion criteria for the survey were age 18-85, both male and female patients, patients receiving chemo or radiotherapy, having surgical cancer treatment, and outpatients in post-treatment phase waiting for a first check-up - i.e. the different phases of the illness 
trajectory. The sample size was estimated with the help of the biometrical attributes of the instrument. Difference and change of $10 \%$ were taken as relevant indicators. In the calculations, the significance level of 0.05 and power of 0.80 were applied. Calculations were conducted with SAS 9.1 procedure POWER. The estimated participation rate of informants (80\%) gave a sample size of at least 330. Data were collected during a period of seven months between November 2012 and June 2013.

The general principles of research ethics ${ }^{[40]}$ were applied. Ethical approval from the ethical committee and permissions for data collection from organizations were sought and granted. For the survey, the informants were asked by their nurse to complete the EKHP® questionnaire, as a sign of informed consent, to seal it into an envelope and to give it back to the nurse.

Table 1. Sample demographics distribution in the EKHP ${ }^{\circledR}$ survey data in Finland $(n=332)$ and Spain $(n=483)$

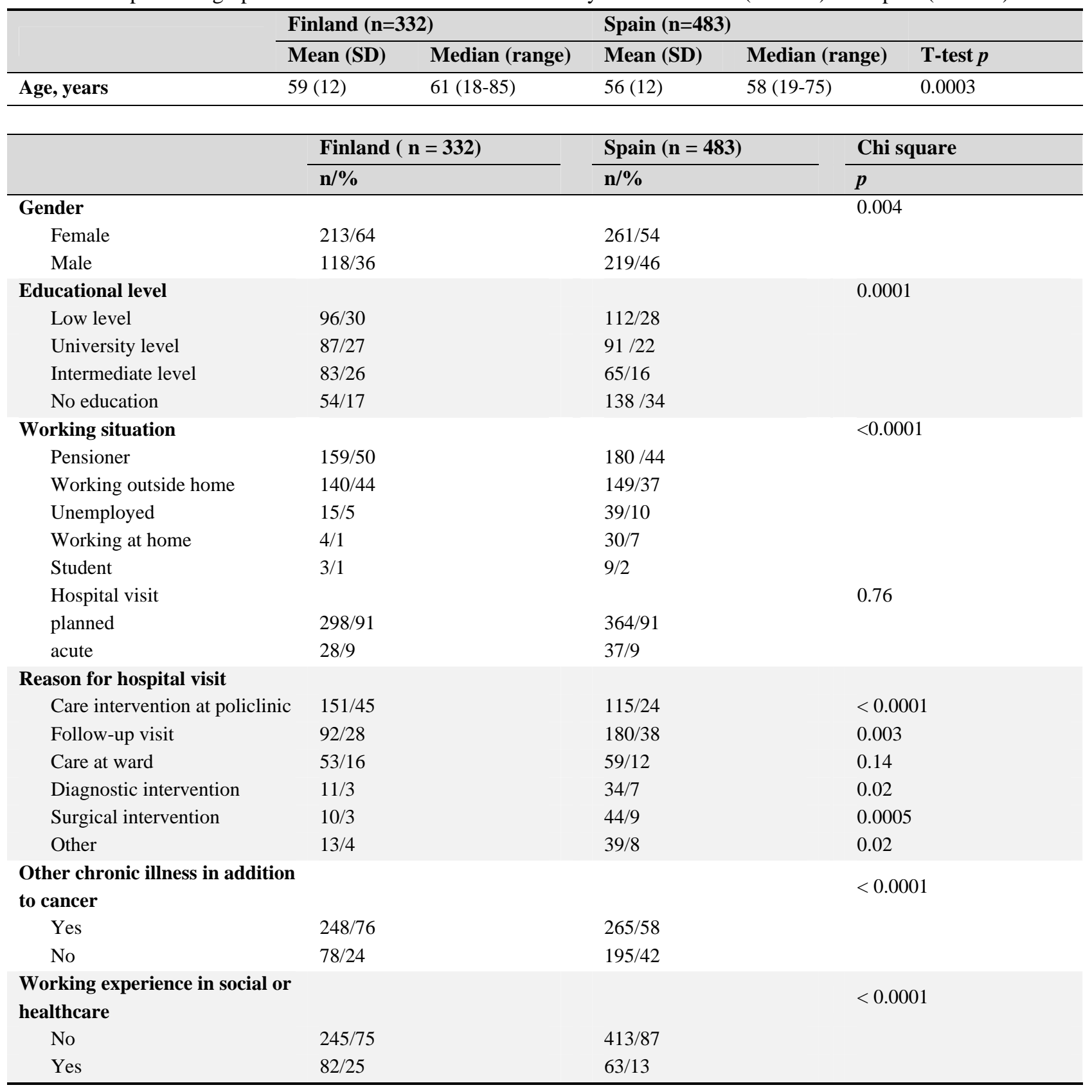


Table 1. (Continued.)

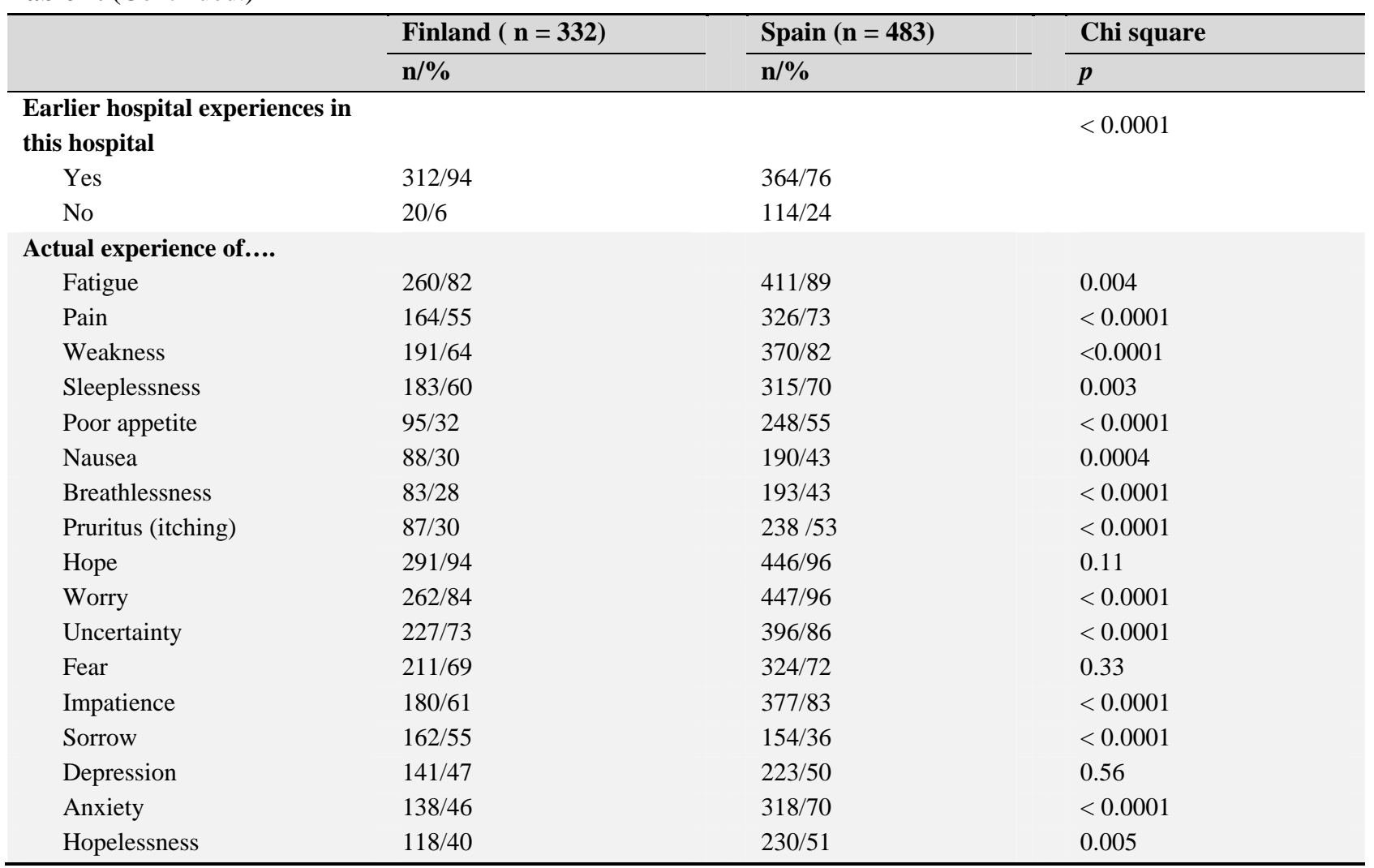

\section{Statistical analyses}

First, the homogeneity of the EKHP® instrument in the Finnish and Spanish oncologic samples was analyzed with Cronbach alphas. Then, the datasets were analyzed with descriptive statistical methods, and possible differences between countries in the background factors were identified with chi-square test or $t$-test. The sum variables were compared between Spain and Finland by means of Wilcoxon Two-Sample test. The associations between the background factors and the sum variables were analyzed by parametrical (analysis of variance, $t$-test) or non-parametrical methods (Wilcoxon, Kruskall-Wallis), depending on the distribution of the variables. Finally, all significant background factors were included in multivariate linear model (regression model). One by one, the non-significant background factors were dropped from the model until all factors in the model were significant. We used $p$-value 0.05 as the limit of significant results.

\section{Results}

\section{Demographic data}

In the Finnish data, the EKHP® ${ }^{\circledR}$ was found to fit well in the oncologic setting (see Table 1). The sum-level Cronbach alphas ranged from 0.78 to 0.94 (see Table 2). The sample $(\mathrm{n}=332)$ demographics distribution is comparable with the actual cancer incidence in Finland. The mean age of informants was 59 years (range 18-85), i.e., they were past middle-age, and the majority of them had, in addition to cancer, some other chronic disease, for example, diabetes, asthma, hypertonia, rheumatoid arthritis, or colitis. The majority of informants (73\%) answered to the questionnaire in connection with a policlinic intervention, such as chemotherapy or radiation therapy, or at a follow-up visit during or after the cancer management process. In the survey data, $92 \%$ of patients experienced actual clinical symptoms and $92 \%$ of patients some kind of emotional distress. Twelve possible informants are known to have declined from completing the questionnaire because of tiredness, all of them were over 75 years, and four due to lack of time. 
Table 2. Knowledge expectations, perceived clinical symptoms and emotional distress, and nurse advocacy expectations in the samples in Finland $(n=332)$ and Spain $(n=483)$

\begin{tabular}{|c|c|c|c|c|c|c|c|c|c|c|}
\hline \multirow{2}{*}{$\begin{array}{l}\text { Knowledge } \\
\text { expectations }\end{array}$} & \multirow{2}{*}{$\begin{array}{l}\begin{array}{l}\text { Number } \\
\text { of items } \\
\text { /sum }\end{array} \\
9 \\
\end{array}$} & \multicolumn{2}{|c|}{$\begin{array}{l}\text { Cronbach alpha } \\
\text { in } \\
\text { Finland/Spain }\end{array}$} & \multicolumn{2}{|c|}{$\begin{array}{l}\text { Mean } \\
\text { in Finland/ } \\
\text { in Spain }\end{array}$} & \multicolumn{2}{|c|}{$\begin{array}{l}\text { Median } \\
\text { in Finland/in } \\
\text { Spain }\end{array}$} & \multicolumn{2}{|c|}{$\begin{array}{l}\text { SD } \\
\text { in Finland/ } \\
\text { in Spain }\end{array}$} & \multirow{2}{*}{ 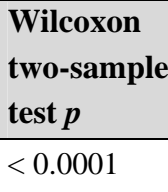 } \\
\hline & & 0.94 & 0.87 & 1.50 & 1.18 & 1.22 & 1 & 0.72 & 0.35 & \\
\hline Functional & 7 & 0.94 & 0.89 & 1.87 & 1.27 & 1.71 & 1 & 0.82 & 0.47 & $<0.0001$ \\
\hline Experiential & 6 & 0.87 & 0.87 & 1.87 & 1.48 & 1.67 & 1 & 0.83 & 0.72 & $<0.0001$ \\
\hline Ethical & 3 & 0.93 & 0.91 & 1.80 & 1.40 & 1.67 & 1.22 & 0.74 & 0.55 & $<0.0001$ \\
\hline Social & 9 & 0.91 & 0.77 & $\underline{1.99}$ & 1.49 & 1.83 & 1.33 & 0.80 & 0.63 & $<0.0001$ \\
\hline Economical & 6 & 0.93 & 0.92 & 1.87 & $\underline{1.57}$ & 1.75 & 1.17 & 0.82 & 0.80 & $<0.0001$ \\
\hline $\begin{array}{l}\text { Actual clinical } \\
\text { symptoms }{ }^{\#}\end{array}$ & 9 & 0.78 & 0.83 & 3.27 & 2.71 & 3.88 & 2.67 & 0.55 & 0.68 & $<0.0001$ \\
\hline $\begin{array}{l}\text { Subjective } \\
\text { emotional } \\
\text { distress }{ }^{\#}\end{array}$ & 9 & 0.84 & 0.79 & 2.96 & 2.54 & 3.10 & 2.56 & 0.64 & 0.60 & $<0.0001$ \\
\hline $\begin{array}{l}\text { Nurse advocacy } \\
\text { expectations }^{\epsilon}\end{array}$ & & Finland & Spain & Finland & Spain & Finland & Spain & SD & SD & $p$ \\
\hline $\begin{array}{l}\text { Knowledge about } \\
\text { right to } \\
\text { self-determination }\end{array}$ & 4 & 0.76 & 0.77 & $\underline{3.64}$ & $\underline{3.94}$ & 3.75 & 4.25 & 0.89 & 0.98 & $<0.0001$ \\
\hline $\begin{array}{l}\text { Knowledge about } \\
\text { advocacy }\end{array}$ & 4 & 0.75 & 0.80 & 4.27 & 4.37 & 4.5 & 4.75 & 0.66 & 0.81 & 0.0003 \\
\hline $\begin{array}{l}\text { Perceived } \\
\text { empowerment in } \\
\text { self-determination } \\
\text { and self-advocacy }\end{array}$ & 5 & 0.79 & 0.81 & 4.01 & 4.40 & 4.20 & 4.60 & 0.72 & 0.74 & $<0.0001$ \\
\hline $\begin{array}{l}\text { Self-determinatio } \\
\mathrm{n} \text { expectations }\end{array}$ & 4 & 0.91 & 0.90 & 4.04 & 4.63 & 4.0 & 5.0 & 0.86 & 0.69 & $<0.0001$ \\
\hline $\begin{array}{l}\text { Counseling } \\
\text { advocacy } \\
\text { expectations }\end{array}$ & 4 & 0.91 & 0.88 & 3.88 & 4.61 & 4.0 & 5.0 & 0.96 & 0.68 & $<0.0001$ \\
\hline $\begin{array}{l}\text { Protective and } \\
\text { reactive advocacy } \\
\text { expectations }\end{array}$ & 4 & 0.90 & 0.92 & 4.33 & 4.72 & 4.5 & 5.0 & 0.81 & 0.62 & $<0.0001$ \\
\hline
\end{tabular}

* Knowledge expectations: Totally agree 1, Nearly agree 2, Nearly disagree 3, Totally disagree 4

\# Actual experience: Very much 1, Some 2, Not so much 3, Not at all 4

$€$ Nurse advocacy expectations: Totally agree 5 , Nearly agree 4, Neither agree nor disagree 3, Nearly disagree 2, Totally disagree 1

In the Spanish data, the EKHP® was also found to fit well in the oncologic setting (see Table 1). The sum-level Cronbach alphas ranged from 0.77 to 0.92 (see Table 2). In the Spanish data $(n=483)$, the sample demographics distribution is comparable with the actual cancer incidence in Spain. The age of the informants (mean 56 years, range 19-75) was a little lower than in Finland, and the majority of Spanish informants (58\%) had other chronic diseases, for example, diabetes, asthma or osteoporosis. The majority of informants completed the questionnaire during a planned visit to the hospital, and $24 \%$ of them had no earlier care experience in that hospital. In the survey data, $93 \%$ of patients experienced actual clinical symptoms, especially in the age group 31-40, and $97 \%$ of patients some kind of emotional distress, with the highest prevalence in the age group 31-40. Altogether 155 possible informants are known to have declined from filling in the questionnaire for the following main reasons: $29 \%(n=45)$ did not understand the questions, $22 \%(n=34)$ were not in a good mood for filling in the questionnaire, and 15.5\% ( $\mathrm{n}=24)$ were not interested in the research project. Another 22 informants had filled in the questionnaire incompletely and they were excluded from data analyses. 
Table 3. Demographical, situational and clinical factors associated with knowledge expectations in Finland and in Spain. Results of multivariate linear models

\begin{tabular}{|c|c|c|c|c|}
\hline \multirow{2}{*}{$\begin{array}{l}\text { Sum variable in } \\
\text { EKHP® }\end{array}$} & Independent factors & Multivariate & Independent factors & Multivariate \\
\hline & Finland $(n=332)$ & model, $p$ & Spain $(n=483)$ & model, $p$ \\
\hline \multirow{2}{*}{$\begin{array}{l}\text { Bio- } \\
\text { physiological 1) }\end{array}$} & Older age + & 0.0004 & - & \\
\hline & Fear + & 0.007 & & \\
\hline \multirow{3}{*}{ Functional } & Older age + & 0.005 & Older age + & 0.02 \\
\hline & Low educational background + & 0.007 & & \\
\hline & Admission for surgical intervention + & 0.02 & & \\
\hline \multirow{5}{*}{ Experiential } & Older age + & 0.0009 & Earlier chronic illness + & 0.01 \\
\hline & Low educational background + & 0.0009 & & \\
\hline & Acute admission + & 0.03 & & \\
\hline & Admission for surgical intervention + & 0.03 & & \\
\hline & Anxiety + & 0.0001 & & \\
\hline \multirow{4}{*}{ Ethical } & Older age + & 0.002 & Older age + & 0.03 \\
\hline & Low educational background + & 0.02 & $\begin{array}{l}\text { First hospital } \\
\text { admission + }\end{array}$ & 0.002 \\
\hline & Acute admission + & 0.03 & & \\
\hline & Admission for surgical intervention + & 0.01 & & \\
\hline \multirow{4}{*}{ Social } & Low educational background + & 0.001 & Older age + & 0.006 \\
\hline & Pension + & 0.005 & & \\
\hline & Acute admission + & 0.02 & & \\
\hline & Admission for surgical intervention + & 0.03 & & \\
\hline \multirow[b]{2}{*}{ Economical } & Low educational background + & 0.004 & Older age + & 0.004 \\
\hline & Acute admission + & 0.0006 & $\begin{array}{l}\text { First hospital admission } \\
+\end{array}$ & 0.001 \\
\hline \multirow{3}{*}{$\begin{array}{l}\text { Actual clinical } \\
\text { symptoms 1) }\end{array}$} & Admission to ward + & 0.01 & Follow-up visit + & 0.01 \\
\hline & Follow-up visit + & 0.002 & $\begin{array}{l}\text { First hospital } \\
\text { admission }+\end{array}$ & 0.0005 \\
\hline & & & $\begin{array}{l}\text { Age } 31-60 \text { years }+ \text {, age } \\
30 \text { or } 61 \text { - years - }\end{array}$ & 0.0004 \\
\hline \multirow{3}{*}{$\begin{array}{l}\text { Subjective } \\
\text { emotional } \\
\text { distress 2) }\end{array}$} & Female gender + & 0.0003 & $\begin{array}{l}\text { Age } 31-60 \text { years }+ \text {, age } \\
30 \text { or } 61 \text { - years - }\end{array}$ & 0.007 \\
\hline & Earlier chronic illness - & 0.02 & & \\
\hline & Follow-up visit + & 0.02 & & \\
\hline
\end{tabular}

Nurse advocacy expectations

\begin{tabular}{lllll} 
& Basic level professional education + & 0.03 & Earlier chronic illness - & 0.03 \\
$\begin{array}{l}\text { Knowledge about } \\
\text { right to }\end{array}$ & First hospital admission + & 0.02 & Fatique - & 0.03 \\
self-determination & Weakness - & 0.02 & Breathlessness - & 0.04 \\
& Poor appetite - & 0.04 & Sorrow - & 0.05 \\
\hline
\end{tabular}


Table 3. (Continued.)

\begin{tabular}{|c|c|c|c|c|}
\hline \multirow{2}{*}{$\begin{array}{l}\text { Sum variable in } \\
\text { ЕКНР® }\end{array}$} & Independent factors & Multivariate & Independent factors & Multivariate \\
\hline & Finland $(\mathrm{n}=332)$ & model, $p$ & Spain $(n=483)$ & model, $p$ \\
\hline \multirow{3}{*}{$\begin{array}{l}\text { Knowledge about } \\
\text { advocacy }\end{array}$} & Low educational background + & 0.02 & Fatique - & 0.006 \\
\hline & Pain - & 0.005 & & \\
\hline & Poor appetite - & 0.009 & & \\
\hline \multirow{4}{*}{$\begin{array}{l}\text { Perceived } \\
\text { empowerment } \\
\text { in } \\
\text { self-determination } \\
\text { and self-advocacy }\end{array}$} & Weakness - & 0.009 & Fatique - & 0.0004 \\
\hline & Impatience - & 0.002 & Weakness - & 0.007 \\
\hline & & & Sorrow - & 0.006 \\
\hline & & & & \\
\hline \multirow{2}{*}{$\begin{array}{l}\text { Self-determination } \\
\text { expectations }\end{array}$} & Low educational background + & 0.0003 & $\begin{array}{l}\text { Cancer treatment at ward } \\
\text { - }\end{array}$ & 0.03 \\
\hline & Impatience + & 0.006 & & \\
\hline \multirow{2}{*}{$\begin{array}{l}\text { Counseling } \\
\text { advocacy } \\
\text { expectations }\end{array}$} & Low educational background + & 0.006 & Older age + & 0.02 \\
\hline & Impatience + & 0.003 & First hospital admission - & 0.02 \\
\hline \multirow{3}{*}{$\begin{array}{l}\text { Protective and } \\
\text { reactive } \\
\text { advocacy } \\
\text { expectations }\end{array}$} & First hospital admission + & 0.04 & $\begin{array}{l}\text { Low professional } \\
\text { education }+\end{array}$ & 0.001 \\
\hline & & & $\begin{array}{l}\text { Cancer treatment at ward } \\
\text { - }\end{array}$ & 0.03 \\
\hline & & & First visit to hospital - & 0.004 \\
\hline \multicolumn{5}{|c|}{$\begin{array}{l}+ \text { factor is associated with higher expectations } \\
\text { - factor is associated with lower expectations } \\
1 \text { ) and 2) } \\
+ \text { factor is associated with more symptoms / distress } \\
\text { - factor is associated with less symptoms / distress }\end{array}$} \\
\hline
\end{tabular}

\section{Knowledge expectations}

The results indicate that the Spanish informants had higher knowledge expectations in all sum variables and a higher need for counseling nurse advocacy than the Finnish informants had (see Table 2). However, in both datasets, the highest expectations concerned the bio-physiological knowledge domain, especially as it comes to information about cancer treatment methods. The prevalence of actual clinical symptoms was rather high in both datasets, and in light of this, knowledge expectations concerning symptoms, diagnostic methods and cancer treatment methods were anticipated. Despite the fact that cancer is known to impact several aspects of one's life for a long time, expectations related to knowledge about social issues were the lowest in both datasets. The biggest difference between the Finnish and Spanish datasets was found in the expectations for functional knowledge: the Spanish informants expressed more knowledge expectations in this domain, with a focus on self-care resources. All other domains of empowering knowledge (experiential, ethical and economical) were also expected, but none of them received higher mean values than the others within the datasets.

Certain demographical, clinical and situational factors were identified as having statistically significant relationships with the informants' knowledge expectations (see Table 3). However, there were only few similarities between the Finnish and Spanish data. In both datasets, demographical factors such as older age, lower educational background or low professional background were associated with several knowledge expectation domains. Some statistical associations between situational factors (i.e., the phase of illness trajectory) and perceived knowledge or advocacy expectations were also identified. In the Finnish data, positive statistical correlations were found between admission for surgical intervention and 
higher expectations for all knowledge sum variables but bio-physiological and economical. Furthermore, acutely admitted patients had higher expectations for experiential, ethical, social and economical knowledge. Patients visiting a policlinic for a follow-up had significantly more clinical symptoms and emotional distress than the other patients. In Spain, patients had higher expectations in terms of the sum variable bio-physiological knowledge, but no single factor explained which patients in particular would have preferred this knowledge. The statistical analyses showed that patients visiting a hospital for a first time had higher expectations related to ethical and economical knowledge. Spanish patients experiencing first hospital admission had more actual clinical symptoms. In Finland, actual emotional distress items, such as fear, depression or anxiety, were found to have statistically significant relationships with functional and experiential knowledge domains. Interestingly, in the Spanish data, there were no statistical relationships between any of the sum variables and emotional distress. This was despite the fact that the prevalence of all subjective emotional distress items, except for sorrow, was higher in Spain than in Finland.

\section{Advocacy expectations}

In both datasets, nurse advocacy expectations on sum level were rather similar (see Tables 2). The proactive and reactive advocacy needs were higher than the other advocacy related expectations. Spanish informants expected more counseling advocacy, however, there were only marginal differences between the datasets in the question about perceived empowerment in self-determination and advocacy. Some demographical, situational and clinical factors were identified to have statistically significant associations also with the informants' nurse advocacy expectations (see Table 3). In both datasets, clinical symptoms such as weakness and breathlessness were in statistical correlation to less knowledge expectations concerning the right to self-determination and advocacy, and patients with emotional distress or certain clinical symptoms perceived themselves less empowered in self-determination and self-advocacy than patients feeling well. In Finland, informants with lower level of professional education and those visiting the hospital for the first time had higher expectations on knowledge about the right to self-determination and knowledge about advocacy. In Spain, informants' clinical symptoms were statistically associated both with less knowledge expectations concerning the right to self-determination and with less knowledge expectations concerning advocacy.

In Finland, statistical relationships were observed between lower educational background and higher expectations on self-determination and counseling advocacy. Informants perceiving impatience had higher expectations on self-determination and counseling advocacy when informants at their first hospital admission anticipated proactive and reactive advocacy. In Spain, informants with their first hospital admission or treatment at ward had less of these expectations. In both datasets, lack of actual clinical symptoms had a correlation with knowledge expectations concerning the right to self-determination and advocacy as such.

\section{Discussion}

The aim of this study was to explicate adult cancer patients' knowledge expectations and nurse advocacy expectations and to identify significant demographical, situational and clinical factors related to these expectations during the illness trajectory. On the basis of the survey datasets obtained from three hospitals in two countries, Finland and Spain, it appears that adult cancer patients have a vast range of knowledge and advocacy expectations prior to, during and after cancer management. Especially patients at an older age or with lower educational background were found to have higher knowledge expectations concerning several knowledge domains. Thus, both in Finland and Spain, elderly cancer patients acknowledge that their knowledge base does not satisfy the individuals themselves.

Consistent with the previous research ${ }^{[17]}$, the highest expectations in both datasets concerned bio-physiological knowledge. Cancer patients in both countries wish to be informed about bio-physiological issues so that they can understand their illness and alternative treatment options, and navigate in the health care system. This might be connected to the prevalence of actual clinical symptoms, higher age or frequency of concurrent chronic illnesses ${ }^{[26,27]}$, which all were 
prominent in both datasets, although the majority of informants were already undergoing the cancer treatment or policlinic follow-up phases.

The major difference between the countries concerned functional knowledge expectations. Spanish informants expected more knowledge about self-care resources - also those informants with concurrent chronic illnesses. This might be one important factor to include in the Spanish health services because it is possible that self-care efforts are hindered by the lack of knowledge about the illness and its management (bio-physiological knowledge). The two countries also differed in knowledge expectations concerning social issues. In Finland it was the least expected category, whereas in Spain, it was placed in the middle of the knowledge expectation list. This is interesting since the Hispanic culture is considered to be family-centered ${ }^{[32]}$. However, in the instrument applied in this study, four of the six items measuring social knowledge expectations focus on social support needs that fall outside of the patients' closer social support system, such as family. Thus this result may be interpreted as indication of satisfactory family support systems in both countries, and less knowledge expectations about social support system outside the close one.

Ethical knowledge expectations were prominent in both countries. As it comes to nurse advocacy expectations, the proactive and reactive advocacy needs were higher than other advocacy-related expectations, and expectations related to knowledge about self-determination were lower in both samples. In other words, cancer patients expect to be cared for, especially the patients who perceive themselves vulnerable due to age, cognitive disempowerment, clinical symptoms due to illness or its treatment, or emotional distress. Knowledge expectations concerning advocacy were high in both samples, and the Spanish informants had slightly higher self-determination expectations and significantly higher counseling nurse advocacy expectations than the Finnish informants. This is a logical outcome, given the earlier described results about Spanish informants' higher knowledge expectations for all sum variables. Despite this, the Spanish informants more often perceived themselves empowered in self-determination and self-advocacy than the Finnish informants. This result may be understood in relation to their higher expectations on bio-physiological and functional knowledge.

The Finnish informants seemed to have more knowledge in all of the categories measured than the Spanish informants, who also expressed higher counseling advocacy expectations. The slight differences between the datasets can be explained with reference to cultural differences: in Hispanic culture, cancer is not as openly discussed as it is in Finland and this may affect patients' information search strategies ${ }^{[12]}$ and also patient education praxis ${ }^{[31]}$. However, the individual demographical, situational and clinical factors were found to affect significantly both the knowledge expectations and advocacy expectations. In both samples but especially in Finland, informants experiencing an acute or first hospital admission expected more knowledge about experiential, ethical, social and economical issues as well as about right to self-determination and proactive and reactive advocacy. Furthermore, patients with actual clinical symptoms or emotional distress perceived themselves less empowered. The results about perceived clinical symptoms and emotional distress in relation to knowledge expectations concerning self-determination and advocacy were slightly different in the two datasets. It seems that the worse the patients feel clinically and emotionally, the less they expect knowledge about how to self-advocate or get a nurse advocate. Interestingly, in Finland the proactive or reactive advocacy expectations were higher during the first hospital admission when in Spain informants visiting hospital for a first time did not have these expectations.

\section{Conclusions and implications for practice}

For the above discussed reasons, it is vital that patient education in oncologic context be based on nurses' continuous analysis of patients' knowledge expectations and advocacy expectations in light of their demographical background, the actual phase of illness trajectory, and perceived emotional distress and clinical symptoms. Cancer is a long-term illness with a major impact on patients' life and empowerment to self-care. Therefore cancer patients wish to be informed about bio-physiological issues so that they can understand their illness and the treatment options, navigate in the health care 
system, be engaged into cancer care with means of self-care activities, and to contact social or financial support systems outside of family, if needed.

However, patient education is not enough: what comes to nurse advocacy expectations, cancer patients expect to be cared for both proactively and reactively, especially the patients who perceive themselves vulnerable due to age, cognitive disempowerment, clinical symptoms due to illness or its treatment, or emotional distress. It seems that they do not prefer self-advocacy knowledge but rather to be safe-guarded. This is understandable due the nature of the illness and its' medical care.

Some differences between two culturally different settings were found: the Finnish informants seemed to have more knowledge in all of the categories measured than the Spanish informants, who also expressed more knowledge about self-care issues and higher counseling advocacy expectations. This might be understood in light of educational differences. However, systematical cancer patient education at least on bio-physiological issues and functional self-care issues could be important to develop in the Spanish health services. In the Finnish dataset, there was evidence that impatience had a statistical relationship with self-determination expectations and counseling advocacy expectations. It can be asked if such an emotional experience is a result of knowledge related disempowerment - or vice versa.

\section{I mplications for research}

Now cancer patients' knowledge and advocacy expectations are shown to vary during the illness trajectory due to demographical, situational and clinical factors. The next demand is to structure this evidence into an instrument to be used in everyday cancer nursing. However, cancer nurses are not alone responsible for patient education or education outcomes: an inter-professional approach to patient-centered education should be structured and applied in order not only to make sure that patients are fully informed about their condition and treatment options but to ensure that patients feel respected in the clinical encounter and that cancer care is planned together with patients.

\section{Limitations}

This study has certain limitations. First, the majority of informants in this survey were middle-aged or older, so the results do not cover younger cancer patients' knowledge expectations and advocacy expectations. Secondly, the subculture of informants is not known, although it is evident that there are different subcultures both in Finland and Spain. In Finland, for example, there are a lot of inhabitants originally from Estonia and Lithuania, where traditional medical cancer care is accompanied with alternative care methods and people do not only rely on doctors but also self-help and religion. In Spain, South-American and other subcultures also emerge. Therefore, the current research results can be influenced by different subcultural knowledge expectations. In addition, the majority of informants in this survey already had some experience of cancer management, or were in the follow-up visit phase of illness trajectory. The results of this study are therefore mainly based on the opinions of individuals undergoing later illness trajectory. However, informants waiting for a diagnostic intervention or surgery also participated in the survey.

\section{References}

[1] Nordcan 2011. Avaible from: http://www-dep.iarc.fr/NORDCAN/FI/graph7.asp?cancer=410\&male=1\&female=2\&incidence=1\&stat=1\&age_from=5\&age_to =16\&period=2011\&grid=1\&registry=1\&submit=\%A0\%A0Suorita\%A0\%A0 5th August 2013.

[2] Cancer Register. 2013. Avaible from: http://www.cancer.fi/syoparekisteri/tilastot/grafiikkaa-syopa-suomessa-2011-j/miesten-yleisimpien-syopien-ikav/ 5th August 2013.

[3] Malvezzi M, Bertuccio P, Levi F, La Vecchia C, Negri E. European cancer mortality predictions for the year 2013. Annals of Oncology. 2013; 24 (3): 792-800. PMid:23402763 http://dx.doi.org/10.1093/annonc/mdt010 
[4] SEOM Sociedad española de oncología médica 2013. Avaible from:

http://www.seom.org/es/prensa/el-cancer-en-espanyacom/104018-el-cancer-en-espana-2013. September 15th of 2013.

[5] Milne D, Sheeran L, Holmes M, Tidhar G, Sanchia A. Trialling a patient-centered cancer care website in an acute cancer care setting. Journal of Research in Nursing. 2012; 17(6): 538-554. http://dx.doi.org/10.1177/1744987112458668

[6] Woodward, E. 2011. Cancer: Patient Information. The Joanna Briggs Institute 15.12. 2011.

[7] Andreassen S, Randers I, Näslund E, Stockeld D, Mattiasson A-C. Information needs following a diagnosis of oesophageal cancer; self-perceived information needs of patients and family members compared with the perceptions of healthcare professionals: a pilot study. European Journal of Cancer Care. 2007; 16: 277-285.

PMid:17508949 http://dx.doi.org/10.1111/j.1365-2354.2006.00742.x

[8] Cramer Bertram C. Informational needs and the experiences of women with abnormal Papanicolaou smears. Journal of the American Academy of Nurse Practitioners. 2008; 20: 455-462. PMid:18786022 http://dx.doi.org/10.1111/j.1745-7599.2008.00341.x

[9] Fazil Q, Wallace LM, Singh G, Ali Z, Bywaters P. Empowerment and advocacy: reflections on action research with Bangladeshi and Pakistani families who have children with severe disabilities. Health and Social Care in the Community. 2004; 12(5): $389-397$. PMid:15373817 http://dx.doi.org/10.1111/j.1365-2524.2004.00508.x

[10] Best JB. Cognitive psychology (5th ed.).CA: Wadsworth Publishing Company, Belmont; 1999: 15-17.

[11] Vaartio-Rajalin H, Iire L, Lehtonen K, Minn H. 2014. Oncologic patients' cognitive capacities and knowledge expectations during illness trajectory - analysis of critical moments and factors. Accepted in 1/2014 to Cancer Nursing Practice.

[12] Sainio C, Eriksson E. Keeping cancer patients informed: a challenge for nursing.European Journal of Oncology Nursing. 2003; 7(1): 39-49. http://dx.doi.org/10.1054/ejon.2002.0218

[13] Pavlish C, Ceronsky L. Oncology Nurses' Perceptions of Nursing Role and Professional Attributes in Palliative Care. Clinical Journal of Oncology Nursing. 2009; 13(4): 404-412. PMid:19648096 http://dx.doi.org/10.1188/09.CJON.404-412

[14] Sutherland G, Hill D, Morand M, Pruden M \& McLachlan S. Assessing the unmet supportive care needs of newly diagnosed patients with cancer. European Journal of Cancer Care. 2009; 18 (6): 577-584. PMid:19549286 http://dx.doi.org/10.1111/j.1365-2354.2008.00932.x

[15] Boyes A, Girgis A \& Lecathelinasis C. Brief assessment of adult cancer patients' perceived needs: development and validation of the 34-item Supportive Care Needs Survey (SCNS-SF34). Journal of Evaluation in Clinical Pracrice. 2009; 15: 602-606. PMid:19522727 http://dx.doi.org/10.1111/j.1365-2753.2008.01057.x

[16] Arraras JL, Wright S, Greimel E, Holzner B, Kuljanic-Vlasic K, Velikova G, Eisemann M, Visser A. Development of questionnaire to evaluate the information needs of cancer patients: the EORTC questionnaire. Patient Education and Counseling 2004; 54(2): 235-241. http://dx.doi.org/10.1016/S0738-3991(03)00240-4

[17] Mesters van den Borne B, Maarten De B, Pruyn J. Measuring information needs among cancer patients. Patient Education and Counseling. 2001; 43: 253-262.

[18] Galloway S, Graydon J, Harrison D, Evans-Boyd B, Palmer-Wickham S, Rich-van-der Bij L, West P, Blair A. Informational needs of women with a recent diagnosis of breast cancer: development and initial testing of a tool. Journal of Advanced Nursing. 1997; 25: 1175-1183. PMid:9181414 http://dx.doi.org/10.1046/j.1365-2648.1997.19970251175.x

[19] Thomas R, Kaminski E, Stanton E. \& Williams M. Measuring information strategies in oncology - developing an information satisfaction questionnaire. European Journal of Cancer care. 2004; 13, 65-70.

http://dx.doi.org/10.1111/j.1365-2354.2004.00445.x

[20] Degner LF, Kristjanson LJ, Bowman D, Sloan JA, Cariiere KC, O’Neil J, Bilodeau B, Watson P, Mueller B. Information needs and decisional preferences in women with cancer. JAMA. 1997; 277: 1485-1492. PMid:9145723 http://dx.doi.org/10.1001/jama.1997.03540420081039

[21] Galloway SC, Bubela N, McKibbon A, McCay E, Ross E. Perceived information needs and affect of symptoms on activities after surgery for lung cancer. Canadian Oncology Nursing Journal. 1993; 3: 116-119. http://dx.doi.org/10.5737/1181912x33116119

[22] Vogel BA, Bengel J, Helmes AW. Information and decision making: patients' needs and experiences in the course of breast cancer treatment. Patient Education \& Counseling. 2008; 71(1): 79-85. PMid:18191933 http://dx.doi.org/10.1016/j.pec.2007.11.023

[23] Oxford Dictionary of Nursing. Oxford: Oxford University Press; 2012.

[24] Vaartio, H, Leino-Kilpi, H., Suominen, T. \& Salanterä, S. Nursing advocacy - how is it defined by patients and nurses, what does it involve and how is it experienced. Scandinavian Journal of Caring Sciences. 2006; 20(3): 282-291. PMid:16922982 http://dx.doi.org/10.1111/j.1471-6712.2006.00406.x

[25] Hanks RG. Sphere of nursing advocacy model. Nursing Forum. 2005; 40(3): 75-78. PMid:16271118 http://dx.doi.org/10.1111/j.1744-6198.2005.00018.x 
[26] O`Connor T, Kelly B. Bridging the gap: a study of general nurses’ perceptions of patient advocacy in Ireland. Nursing Ethics. 2005; 12(5): 453-467. http://dx.doi.org/10.1191/0969733005ne814oa

[27] Wheeler P. Is advocacy at the heart of professional practice? Nursing Standard. 2000; 14(24): 39 -41. PMid:11974263 http://dx.doi.org/10.7748/ns2000.05.14.36.39.c2844

[28] Wilson V. Cognitive impairment in patients with diabetes. Nursing Standard. 2012; 27(15-17): 44-48. PMid:23346706 http://dx.doi.org/10.7748/ns2012.12.27.15.44.c9484

[29] Douw L, Klein M, Fagel SAA, van den Heuvel J, Taphoorn MJB, AAronson NK, Postma TJ, Vandertop WP, Mooij JJ, Boerman, RH, Beute GN, Sluimer JD, Slotman BJ, Reijneveld JC, Heimans JJ. Cognitive and radiological effects of radiotherapy in patients with low-grade glioma: long-term follow-up. Lancet Neurologica. 2009; 8: 810-818. http://dx.doi.org/10.1016/S1474-4422(09)70204-2

[30] Bender CM, Thelen BD. Cancer and Cognitive changes: the complexity of the problem. Seminars in Oncology Nursing. 2013; 29(4): 232-237. PMid:24183154 http://dx.doi.org/10.1016/j.soncn.2013.08.003

[31] Im, Eun-Ok, Hyun-Ju L, Wen-Miao L. An Online Forum Exploring Needs for Help of Patients With Cancer: Gender and Ethnic Differences. Oncology Nursing Forum. 2008; 35(4): 653- 660. PMid:18591169 http://dx.doi.org/10.1188/08.ONF.653-660

[32] Pinquart M, Sorensen S. Ethnic differences in stressors, resources, and psychological outcomes of family caregiving: A meta-analysis. Gerontologist. 2005; 45(1): 90-106. http://dx.doi.org/10.1093/geront/45.1.90

[33] Fernández, M. E., Gonzales, A, Tortolero-Luna G, Williams J, Saavedra-Embesi M, Chan W, Vernon SW. Effectiveness of Cultivando la Salud: A breast and cervical cancer screening promotion program for low-income Hispanic women. American Journal of Public Health. 2009; 99: 936-943. PMid:19299678 http://dx.doi.org/10.2105/AJPH.2008.136713

[34] Kuokkanen L, Leino-Kilpi H. Power and empowerment in nursing: three theoretical approaches. Journal of Advanced Nursing. 2000; 31(1): 235-244. PMid:10632814 http://dx.doi.org/10.1046/j.1365-2648.2000.01241.x

[35] Leino-Kilpi H, Luoto E, Katajisto J. Elements of empowerment and MS patients. Journal of Neuroscience Nursing. 1998; 18: 116-123. Available from: http://www.utu.fi/en/units/med/units/hoitotiede/research/projects/epe/Pages/home.aspx http://dx.doi.org/10.1097/01376517-199804000-00005

[36] Coughlan M, Cronin P, Ryan F. Survey research: process and limitations. International Journal of Therapy and Rehabilitation. 2009; 16 (1): 9-15.

[37] Leino-Kilpi H, Johansson K, Heikkinen K, Kaljonen A, Virtanen S, Salantera S. Patient education and health-related quality of life. Surgical hospital patients as a case in point. Journal of Nursing Care Quality. 2005; 20(4): 307-316. PMid:16177581 http://dx.doi.org/10.1097/00001786-200510000-00005

[38] Johansson K. Empowering orthopaedic patients through education. Turku University Publication Serie D, Medica - Odontologica, 0355-9483; part 728. Turku: Painosalama; 2006.

[39] World Medical Association World Medical Association. 2008. Declaration of Helsinki - ethical principles for medical research involving human subjects. Available from: www.wma.net http://www.wma.net/en/30publications/10policies/b3/index.html 